\title{
Effects of exogenous phenolic acids on photosystem functions and photosynthetic electron transport rate in strawberry leaves
}

\author{
X.F. LU* , H. ZHANG ${ }^{*}$, S.S. LYU*, G.D. DU*, ${ }^{* *+}$, X.Q. WANG ${ }^{*, * *}$, C.H. WU*, and D.G. LYU $^{*}{ }^{* *}$ \\ College of Horticulture, Shenyang Agricultural University, 110866 Shenyang, Liaoning Province, China* \\ Research Laboratory for Breeding and Physiology-Ecology of Northern Fruit Tree, Shenyang Agricultural University, \\ 110866 Shenyang, Liaoning Province, China**
}

\begin{abstract}
Our study investigated the physiological and biochemical basis for the effects of exogenous phenolic acids on the function of the photosynthetic apparatus and photosynthetic electron transport rate in strawberry seedlings. Potted seedlings of the strawberry (Fragaria $\times$ ananassa Duch.) were used. Syringic acid inhibited net photosynthetic rate and water-use efficiency decreased. Additionally, primary quinone electron acceptor of the PSII reaction centre, the PSII reaction centre and the oxygen evolving complex were also impaired. Both the maximum quantum yield of the PSII primary photochemistry and the performance index on absorption basis were depressed, resulting in reduced function of the photosynthetic electron transport chain. Otherwise, low phthalic acid concentrations enhanced photosynthetic capacity, while high concentrations showed opposite effects. Syringic acid exhibited a higher toxic effect than that of phthalic acid which was more evident at higher concentrations.
\end{abstract}

Additional key words: chlorophyll fluorescence; gas exchange; phenolic acid.

\section{Introduction}

The strawberry fruit is known for its sweet and juicy taste, rich nutrients, and abundant protein and vitamins (Tan et al. 2003). Strawberry is primarily grown as an annual crop. However, long-term continuous cropping at the same plots easily leads to weak growth of strawberry plants, yield reduction, and quality deterioration (the so-called soil sickness). The soil sickness phenomenon is particularly prominent under facility cultivation, which has become a major limiting factor in facility strawberry production (Cao and Wang 2007). Investigation of photosynthetic and physiological mechanism underlying long-term soil sickness is critical for high efficiency and high quality of strawberry facility cultivation.
Phenolic acids have been shown to be important factors that cause crop soil sickness (Schutter et al. 2001, Asao et al. 2008, Han et al. 2008). These compounds primarily originate from decomposition of plant residues and root exudation, among other sources. When they accumulate to a certain amount in the soil, phenolic acids exhibit an inhibitory effect on crop growth during the next cropping season (Inderjit et al. 2003, Hiradate et al. 2005, Asaduzzaman et al. 2012). Zhen (2003) identified six phenolic acids [phthalic acid (PA), p-hydroxybenzoic acid, syringic acid (SA), vanillic acid, ferulic acid, and benzoic acid] among decomposition products of strawberry roots from a plot under continuous strawberry cropping. The

Received 24 July 2016, accepted 7 January 2017, published as online-first 10 March 2018.

${ }^{+}$Corresponding author; phone: +86-24-88487219, fax: +86-24-88487219; e-mail: guodong_du@163.com

Abbreviations: $\mathrm{ABS}$ - reaction center area; $\mathrm{Chl}$ - chlorophyll; $C_{\mathrm{i}}-$ intercellular $\mathrm{CO}_{2}$ concentration; $E$ - transpiration rate; ETR - electron transport rate; $\mathrm{F}_{\mathrm{j}}$ - fluorescence yield at $2 \mathrm{~ms} ; \mathrm{F}_{\mathrm{k}}$ - fluorescence yield at $300 \mu \mathrm{s} ; \mathrm{F}_{\mathrm{m}}$ - maximal fluorescence yield of the light-adapted state; FM - fresh mass; $F_{0}$ - minimal fluorescence yield of the dark-adapted state; $F_{v} / F_{m}$ - maximum quantum yield of PSII primary photochemistry; $g_{\mathrm{s}}$ - stomatal conductance; MR/MR - modulated reflection of PSI at $820 \mathrm{~nm}$; OEC - oxygen evolving complex; PA - phthalic acid; PI $\mathrm{ABS}_{\mathrm{AB}}$ - performance index on absorption basis; $P_{\mathrm{N}}$ - net photosynthetic rate; P700 - the chlorophyll $a$ maximum absorption peak of molecules at $700 \mathrm{~nm} ; \mathrm{RC}$ - the energy absorbed by active reaction center; $\mathrm{SA}$ - syringic acid; $\mathrm{V}_{\mathrm{k}}-$ relative variable fluorescence at $300 \mu \mathrm{s} ; \mathrm{V}_{\mathrm{j}}$ - relative variable fluorescence at the J-step; $\mathrm{VPSI}_{\mathrm{PI}}-\mathrm{MR} / \mathrm{MR}_{0}$ maximal slope descending; $\mathrm{V}_{\mathrm{PSI}+\mathrm{PSII}}-\mathrm{MR}_{\mathrm{MRR}}$ maximal slope increasing; $\mathrm{W}_{\mathrm{k}}$ - relative variable fluorescence at the K-step; WUE - water-use efficiency $\left(=P_{\mathrm{N}} / E\right)$; $\Psi_{\mathrm{o}}-$ the ratio of trapped exciton electrons to other electron acceptors downstream of $\mathrm{Q}_{\mathrm{A}}$.

Acknowledgements: This work was supported by the Science and Technology Bureau China Spark Program of Liaoning Province (201410), and Physiology-Ecology of Northern Fruit Tree of Shenyang Agricultural University, China. 
verification test for phenolic acids showed that the root and shoot growth of tissue-cultured strawberry seedlings was inhibited to a certain degree. Huang et al. (2010) indicated that phenolic acids affected photosystem functions in cowpea (Vigna sinensis) leaves primarily through depressed root functions. When mulberry plants were treated with exogenous o-methoxybenzoic acid, chlorophyll (Chl) fluorescence parameters, such as the primary conversion of light energy by PSII ( $\left.\Phi_{\text {PSII }}\right)$ and electron transport rate (ETR) decreased. These changes resulted in lower ATP and NADPH production in the photosynthetic apparatus, which decreased the carbon assimilation rate and assimilate accumulation (Hu 2013). Moreover, Wang et al. (2015) treated tea crabapple (Malus hupehensis) seedlings with exogenous phlorizin, phloretin, cinnamic acid, phydroxybenzoic acid, and phloroglucinol and found that the total Chl and carotenoid (Car) contents of the leaves decreased after treatments. Moreover, net photosynthetic rate $\left(P_{\mathrm{N}}\right)$, stomatal conductance $\left(g_{\mathrm{s}}\right)$, and water-use efficiency (WUE) of the leaves were lower than the control values to varying degrees. Further analysis revealed that the phenolic acids might have destroyed chloroplasts in the leaves, thereby reducing the $\mathrm{Chl}$ content and inhibiting electron transport between $\mathrm{Q}_{\mathrm{A}}$ and $\mathrm{Q}_{\mathrm{B}}$, leading to a

\section{Materials and methods}

Experimental material: The experiment was conducted at the fruit tree experimental base of Shenyang Agricultural University ( $41^{\circ} 82^{\prime} \mathrm{N}, 123^{\circ} 57^{\prime} \mathrm{E}$, Shenyang, Liaoning Province, China) from April to September in 2015. The daily average temperature was $23-28^{\circ} \mathrm{C}$, the moisture contents of the soil were maintained at $70 \%$ of the field water-holding capacity, which could prevent the plants from drought stress. Seedlings of the strawberry (Fragaria $\times$ ananassa Duch.) of the cultivar 'Hokowase' were provided by the strawberry seedling production base of the Guobang Horticulture Farm in the Shenbei New District, Shenyang. Exogenous phenolic acids were purchased from Sigma (Sigma Chemical Co., St. Louis, MO, USA).

Treatments: We prepared PA and SA solutions at gradient concentrations with a $0.3 \%$ ethanol solution as the solvent according to types and contents of phenolic acids detected in the rhizosphere of strawberry under continuous cropping conditions. Four concentrations were used to simulate phenolic acids accumulated in the soil during continuous strawberry cropping. SA and PA with the index of $1,2,3$, and 4 represented the concentration of 1.0, 3.0, 9.0, and $27.0 \mu \mathrm{g} \mathrm{g}^{-1}$, respectively. $\mathrm{CK}$ is normal management with water.

In April 2015, refrigerated strawberry heeled-in seedlings with four exterior leaves and one interior leaf were transplanted into plastic pots (upper diameter of 20 $\mathrm{cm}$, lower diameter of $16 \mathrm{~cm}$, and height of $30 \mathrm{~cm}$ ). Each pot was filled with $2.0 \mathrm{~kg}$ of common garden soil. Each decreased photosynthetic rate. Allelochemicals also inhibited maximum quantum yield of PSII primary photochemistry $\left(\mathrm{F}_{\mathrm{v}} / \mathrm{F}_{\mathrm{m}}\right)$, ETR, and photosynthetic pigment contents in fern leaves, and the inhibitory effect was more evident with an increasing allelochemical content (Zhang et al. 2016).

The effect of phenolic acids on plants is a hot topic in allelopathy research. Despite reports concerning the effect of phenolic acids on plant photosynthesis (Yang et al. 2002; Blum et al. 2005), it is unclear how different phenolic acids affect the function of the photosynthetic apparatus and thus interfere with the transport rate of photosynthetic electrons between PSII and PSI. According to HPLC method, our preliminary experimental results showed that SA and PA exhibited a significant difference in different years of continuous cropping soil. Therefore, in this study, we investigated the response of photosynthetic parameters in strawberry seedlings to different concentrations of exogenous PA and SA and attempted to clarify the mechanism underlying the effect of phenolic acids on the photosystem functions and photosynthetic ETR in strawberry leaves. The results could provide reference data for an in-depth study regarding the soil sickness mechanism for strawberry.

treatment was performed in a single-plant plot with 30 replications. After $20 \mathrm{~d}$ of rejuvenation, the plants were treated with exogenous phenolic acids by continuous irrigation with the prepared solutions ( $100 \mathrm{~mL}$ per plant) five times at 1 -d intervals. Nine days after treatment, samples were collected to measure the relevant parameters. The pot experiment was performed in a greenhouse. The same amount of water and nutrients was supplemented regularly to ensure normal growth of the strawberry plants. Other management conditions were consistent.

Measurements: The Chl contents of strawberry leaves were measured according to the method described by $\mathrm{Li}$ (2006). After treatments with exogenous phenolic acids, fresh leaves were cut into pieces (removing the midrib). A CIRAS-2 portable photosynthesis system (PP-Systems, USA) was used to measure the photosynthetic parameters of fully expanded functional leaves in the center of palmately compound leaves after $10 \mathrm{~d}$ of phenolic acid treatment. A stable adjustable source of gas was provided by the $\mathrm{CO}_{2}$ cylinder equipped with the photosynthesis system, and the $\mathrm{CO}_{2}$ concentration was controlled at $380 \mu \mathrm{mol} \mathrm{mol}{ }^{-1}$. The PAR was set to $1,200 \mu \mathrm{mol}$ (photon) $\mathrm{m}^{-2} \mathrm{~s}^{-1}$ using an LED light source. PAR, air temperature, leaf temperature, vapour pressure, relative humidity, and other parameters were controlled using the automatic control system of the instrument. The $P_{\mathrm{N}}, g_{\mathrm{s}}$, intercellular $\mathrm{CO}_{2}$ concentration $\left(C_{\mathrm{i}}\right)$, and WUE were measured at 9:00-11:00 h on sunny days. 
An $M-P E A$ multi-function plant efficiency analyser (Hansatech, United Kingdom) was used to measure the Chl fluorescence parameters of functional strawberry leaves following the method of Schansker et al. (2003). After full dark adaptation (30 min), the leaves were exposed to saturation pulse light $\left[3,000 \mu \mathrm{mol}\right.$ (photon) $\mathrm{m}^{-2}$ $\mathrm{s}^{-1}$ ] for $1 \mathrm{~s}$. The parameter values were automatically recorded by the instrument. The following fluorescence parameters were obtained using Biolyzer 4.0 software:

Relative variable fluorescence at the K-step $\left(\mathrm{W}_{\mathrm{k}}\right)$ :

$\mathrm{W}_{\mathrm{k}}=\mathrm{V}_{\mathrm{k}} / \mathrm{V}_{\mathrm{j}}=\left(\mathrm{F}_{\mathrm{k}}-\mathrm{F}_{\mathrm{o}}\right) /\left(\mathrm{F}_{\mathrm{j}}-\mathrm{F}_{\mathrm{o}}\right)$;

Relative variable fluorescence at the J-step $\left(\mathrm{V}_{\mathrm{j}}\right)$ :

$\mathrm{V}_{\mathrm{j}}=\left(\mathrm{F}_{\mathrm{j}}-\mathrm{F}_{\mathrm{o}}\right) /\left(\mathrm{F}_{\mathrm{m}}-\mathrm{F}_{\mathrm{o}}\right)$;

Performance index on absorption basis $\left(\mathrm{PI}_{\mathrm{ABS}}\right)$ :

$\mathrm{PI}_{\mathrm{ABS}}=(\mathrm{RC} / \mathrm{ABS})\left[\Phi_{\mathrm{Po}} /\left(1-\Phi_{\mathrm{Po}}\right)\right]\left[\Psi_{\mathrm{o}} /\left(1-\Psi_{\mathrm{o}}\right)\right] ;$

$\mathrm{F}_{\mathrm{v}} / \mathrm{F}_{\mathrm{m}}=1-\left(\mathrm{F}_{\mathrm{o}} / \mathrm{F}_{\mathrm{m}}\right)=\Phi_{\mathrm{Po}}$

The value of RC/ABS, $\Phi_{\mathrm{Po}_{0}}$, and $\Psi_{\mathrm{o}}$ can be calculated by the $M-P E A$ directly.

\section{Results}

Leaf pigments: Application of exogenous SA (S1-S4) and PA (P1-P4) had a significant effect on photosynthetic pigment synthesis in the strawberry leaves (Table 1). After the SA treatment, all four SA concentrations inhibited photosynthetic pigment synthesis in the leaves; the inhibitory effect was enhanced by increasing the SA concentration. The Chl $a$, Chl $b$, Chl $(a+b)$, and Car contents of the strawberry leaves decreased by 25.8, 28.6, 26.6 , and $12.0 \%$, respectively, after the S4 treatment compared with the control. However, with the exception of $\mathrm{S} 1$, the treatments resulted in markedly higher ratio of Chl $a / b$ than that of the control. Different from the SA treatment, PA promoted the photosynthetic pigment contents in strawberry leaves at low concentrations and inhibited at high concentrations. The treatment with low PA concentrations (P1 and P2) increased the Chl $a, \mathrm{Chl} b$, Chl $(a+b)$, and Car contents; in particular, the Chl $a$
The modulated reflection of PSI at $820 \mathrm{~nm}\left(\mathrm{MR} / \mathrm{MR}_{0}\right)$ was measured to reflect the redox state of the $\mathrm{Chl} a$ maximum absorption peak of molecules at $700 \mathrm{~nm}\left(\mathrm{P}_{700}\right)$ by determining the decrease in the maximum amplitude decreased far red light (Munekage et al. 2004, Zhang et al. 2011). MR/MR maximal slope descending ( $\left.\mathrm{V}_{\mathrm{PSI}}\right)$ and $\mathrm{MR} / \mathrm{MR}_{0}$ maximal slope increasing $\left(\mathrm{V}_{\mathrm{PSI}}+\mathrm{PSII}\right)$ were used to indicate the redox capacity of PSI. $\mathrm{V}_{\text {PSI }}$ was calculated from the falling slope of $M R / \mathrm{MR}_{0}$ in the range of 0.7-3 ms; V VSI+ PSII was calculated from the maximum rising slope of $\mathrm{MR} / \mathrm{MR}_{0}$ in the range of 7-300 ms (Sun et al. 2015).

Data analysis: The data were analysed by one-way analysis of variance (ANOVA) using DPS 7.05. The significance of the differences was determined by Duncan's multiple range test at the significance level $P<0.05$. The data calculations were performed using Excel 2010. Graphs were drawn using Sigma Plot 10.0.

content increased by 14.4 and $12.4 \%$, respectively, compared with the control. In contrast, the high PA concentrations ( $\mathrm{P} 3$ and $\mathrm{P} 4)$ reduced the $\mathrm{Chl} a, \mathrm{Chl} b, \mathrm{Chl}(a+b)$, and Car contents. Significantly higher $\mathrm{Chl} a / b$ values were observed for the PA treatments compared with the control and SA treatments, indicating that the two phenolic acids had a stronger inhibitory effect on $\mathrm{Chl} b$.

Photosynthetic parameters: Treatments with all four concentrations of exogenous SA significantly decreased the $P_{\mathrm{N}}, g_{\mathrm{s}}, C_{\mathrm{i}}$, and WUE in the strawberry leaves compared with the control (Fig. 1). $P_{\mathrm{N}}, g_{\mathrm{s}}$, and WUE exhibited a constantly decreasing trend with the increasing SA concentration. In particular, $P_{\mathrm{N}}$ declined by $16.9,32.6$, 44.9 , and $50.6 \%$ compared with the control values, and significant differences were observed between S1-S4 concentrations. Similarly, the exogenous PA treatment

Table 1. Effects of exogenous phenolic acids on photosynthetic pigment contents of strawberry leaves. Values are means of five replicates \pm SD. Different lowercase letters in the same column indicate significant difference at 0.05 level. SA - syringic acid; $\mathrm{PA}$ - phthalic acid; 1, 2, 3, and 4 represent the concentrations of 1.0, 3.0, 9.0, and $27.0 \mu \mathrm{g} \mathrm{g}^{-1}$, respectively. CK - normal management with water; $\mathrm{Chl}$ - chlorophyll; Chl $a / b$ - the ratio of $\mathrm{Chl} a$ and $\mathrm{Chl} b$.

\begin{tabular}{|c|c|c|c|c|c|}
\hline Treatment & Chl $a\left[\mathrm{mg} \mathrm{g}^{-1}(\mathrm{FM})\right]$ & $\mathrm{Chl} b\left[\mathrm{mg} \mathrm{g}^{-1}(\mathrm{FM})\right]$ & $\operatorname{Chl}(a+b)\left[\mathrm{mg} \mathrm{g}^{-1}(\mathrm{FM})\right]$ & Chl $a / b$ & Carotenoids $\left[\mathrm{mg} \mathrm{g}^{-1}(\mathrm{FM})\right]$ \\
\hline CK & $0.97 \pm 0.03^{\mathrm{ab}}$ & $0.42 \pm 0.04^{\mathrm{ab}}$ & $1.39 \pm 0.03^{b}$ & $2.31 \pm 0.04^{\mathrm{c}}$ & $0.25 \pm 0.01^{\mathrm{a}}$ \\
\hline SA1 & $0.91 \pm 0.08^{\mathrm{ab}}$ & $0.40 \pm 0.02^{\mathrm{ab}}$ & $1.31 \pm 0.10^{\mathrm{bc}}$ & $2.28 \pm 0.05^{\mathrm{c}}$ & $0.30 \pm 0.02^{\mathrm{a}}$ \\
\hline SA2 & $0.88 \pm 0.01^{\mathrm{ab}}$ & $0.36 \pm 0.01^{\mathrm{ab}}$ & $1.24 \pm 0.02^{\mathrm{b}}$ & $2.44 \pm 0.05^{\mathrm{abc}}$ & $0.29 \pm 0.01^{\mathrm{a}}$ \\
\hline SA3 & $0.81 \pm 0.05^{\mathrm{ab}}$ & $0.33 \pm 0.05^{\mathrm{ab}}$ & $1.14 \pm 0.05^{\mathrm{de}}$ & $2.46 \pm 0.08^{\mathrm{abc}}$ & $0.25 \pm 0.02^{\mathrm{a}}$ \\
\hline SA4 & $0.72 \pm 0.14^{\mathrm{b}}$ & $0.30 \pm 0.04^{\mathrm{b}}$ & $1.02 \pm 0.18^{\mathrm{e}}$ & $2.40 \pm 0.08^{\mathrm{bc}}$ & $0.22 \pm 0.03^{\mathrm{a}}$ \\
\hline PA1 & $1.11 \pm 0.08^{\mathrm{a}}$ & $0.45 \pm 0.02^{\mathrm{a}}$ & $1.56 \pm 0.10^{\mathrm{a}}$ & $2.47 \pm 0.05^{\mathrm{abc}}$ & $0.27 \pm 0.02^{\mathrm{a}}$ \\
\hline PA2 & $1.09 \pm 0.01^{\mathrm{a}}$ & $0.44 \pm 0.01^{\mathrm{a}}$ & $1.53 \pm 0.02^{\mathrm{a}}$ & $2.45 \pm 0.05^{\mathrm{abc}}$ & $0.26 \pm 0.01^{\mathrm{a}}$ \\
\hline PA3 & $0.92 \pm 0.05^{\mathrm{ab}}$ & $0.35 \pm 0.05^{\mathrm{ab}}$ & $1.27 \pm 0.05^{\mathrm{bcd}}$ & $2.63 \pm 0.08^{\mathrm{ab}}$ & $0.22 \pm 0.02^{\mathrm{a}}$ \\
\hline PA4 & $0.87 \pm 0.14^{\mathrm{ab}}$ & $0.32 \pm 0.04^{\mathrm{ab}}$ & $1.19 \pm 0.18^{\mathrm{cd}}$ & $2.72 \pm 0.08^{\mathrm{a}}$ & $0.24 \pm 0.03^{\mathrm{a}}$ \\
\hline
\end{tabular}




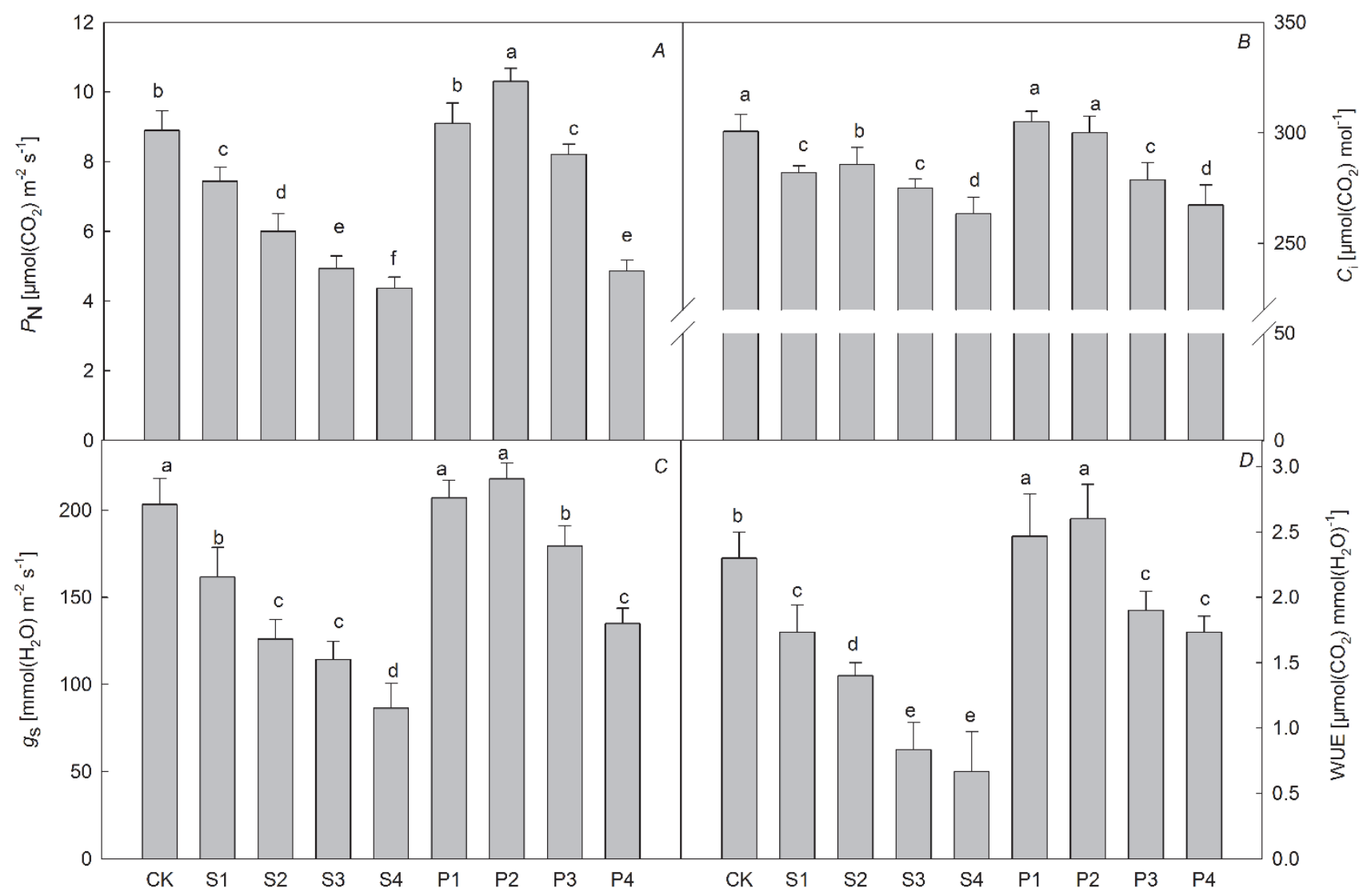

Fig. 1. Effects of exogenous phenolic acids treatments on photosynthetic parameters of strawberry leaves. $\mathrm{S}$ - syringic acid; $\mathrm{P}$ - phthalic acid; $1,2,3$, and 4 represent the concentrations of 1.0, 3.0, 9.0, and $27.0 \mu \mathrm{g} \mathrm{g}{ }^{-1}$, respectively. CK - normal management with water, $C_{\mathrm{i}}$ - intercellular $\mathrm{CO}_{2}$ concentration, $g_{\mathrm{s}}$ - stomatal conductance, $P_{\mathrm{N}}-$ net photosynthetic rate, WUE - water-use efficiency.

stimulated the photosynthetic parameters of strawberry leaves at low concentrations and inhibited at high concentrations. The treatment with the low PA concentrations (P1 and P2) did not significantly increase the $P_{\mathrm{N}}, g_{\mathrm{s}}, C_{\mathrm{i}}$, or WUE; however, the treatment with the high PA concentrations (P3 and P4) significantly decreased the tested photosynthetic parameters and the $P_{\mathrm{N}}$ values of the P3 and P4 treatments accounted for 92.1 and $55.1 \%$ of the control, respectively. The effects of phenolic acids on the photosynthetic parameters were closely related to the type and concentration of phenolic acids.

Chl fluorescence induction curves: A deformation occurred in the curves of $\mathrm{Chl}$ fluorescence induction dynamics in strawberry leaves treated with exogenous phenolic acids (Fig. 2A). After the leaves were exposed to the saturation pulse, the overall trend of the curves was consistent for the different phenolic acid concentrations. However, there were certain differences in the fluorescence intensity of the induction curves, especially between the J phase $(2 \mathrm{~ms})$ and I phase $(30 \mathrm{~ms})$. Moreover, the modulated reflection curves at $820 \mathrm{~nm}$ (reflecting the redox capacity of PSI) showed certain differences between different exogenous phenolic acid treatments and the control (Fig. 2B), suggesting that exogenous phenolic acids might reduce the PSI redox activity in the strawberry leaves. The phenolic acid affected the PSI and PSII function which resulted in changes of the Chl fluorescence induction kinetics and modulated the reflection curve at $820 \mathrm{~nm}$.

PSII Chl fluorescence characteristics: $\mathrm{The}_{\mathrm{k}}$ indicates the activity of OEC and $\mathrm{V}_{\mathrm{j}}$ reflects the PSII acceptor side (electron transported from $\mathrm{Q}_{\mathrm{A}}$ to $\mathrm{Q}_{\mathrm{B}}$ ). $\mathrm{V}_{\mathrm{j}}$ and the $\mathrm{W}_{\mathrm{k}}$ exhibited an upward trend in strawberry leaves with increasing concentrations of exogenous phenolic acids compared with the control (Table 2). After the treatment with the high phenolic acid concentrations, compared with CK, S4 fluorescence parameters increased by $28.8 \%$ in $\mathrm{V}_{\mathrm{j}}$ and $100 \%$ in $\mathrm{W}_{\mathrm{k}}$. However, the $\mathrm{P} 4$ fluorescence parameters were enhanced by $21.2 \%$ in $\mathrm{V}_{\mathrm{j}}$ and $69.2 \%$ in $\mathrm{W}_{\mathrm{k}}$ compared with the control values. 


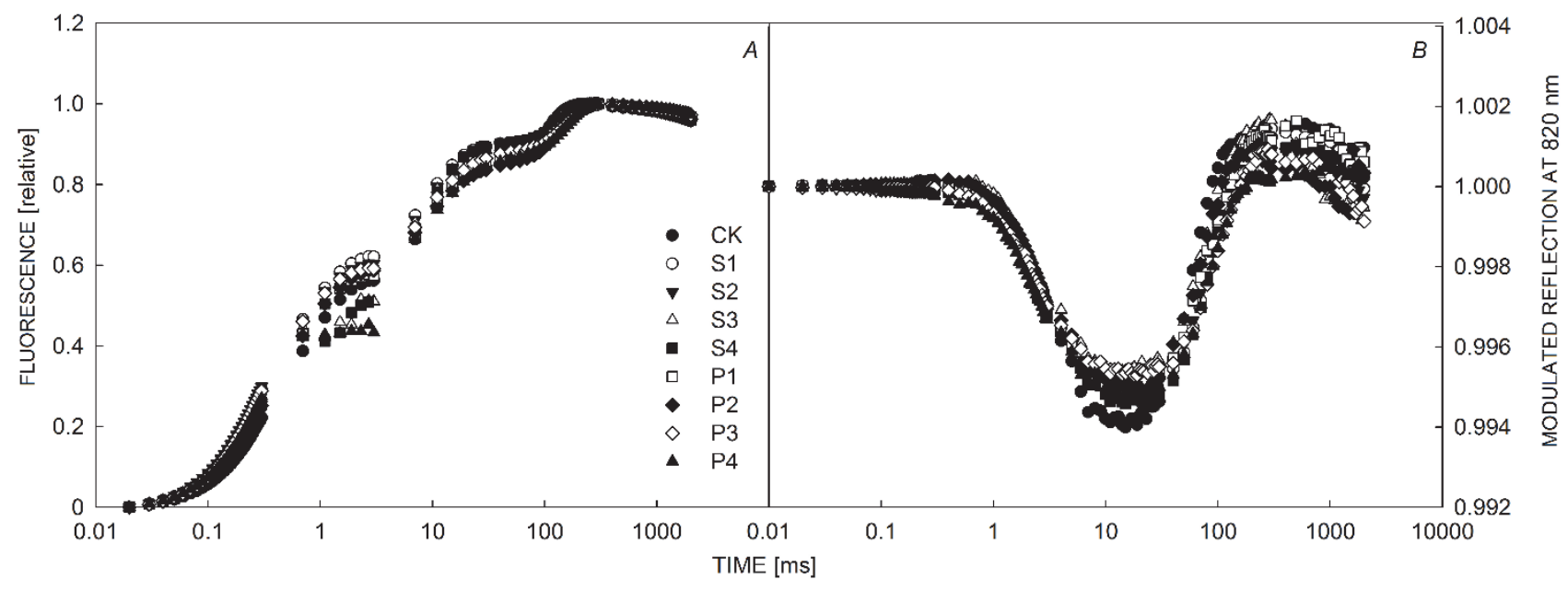

Fig. 2. Effects of exogenousphenolic acids treatments on fluorescence induction kinetics of strawberry leaves. S - syringic acid; P phthalic acid; $1,2,3$, and 4 represent the concentrations of $1.0 \mu \mathrm{g} \cdot \mathrm{g}^{-1}, 3.0 \mu \mathrm{g} \cdot \mathrm{g}^{-1}, 9.0 \mu \mathrm{g} \cdot \mathrm{g}^{-1}$, and $27.0 \mu \mathrm{g} \cdot \mathrm{g}^{-1}$, respectively. CK - normal management with water.

Table 2. Effect of exogenous phenolic acids treatments on chlorophyll fluorescence parameters in strawberry leaves. Values are means of five replicates \pm SD. Different lowercase letters in the same column indicate significant difference at 0.05 level, SA - syringic acid; PA - phthalic acid; 1, 2, 3, and 4 represent the concentrations of 1.0, 3.0, 9.0, and $27.0 \mu \mathrm{g} \mathrm{g}^{-1}$, respectively. CK - normal management with water. $P_{\mathrm{N}}$ - the net photosynthetic rate; $\mathrm{F}_{\mathrm{v}} / \mathrm{F}_{\mathrm{m}}-$ the maximum quantum yield of PSII primary photochemistry; PI $\mathrm{ABS}_{\mathrm{ABS}}-$ the performance index on absorption basis; $\mathrm{W}_{\mathrm{k}}$ - the relative variable fluorescence at the $\mathrm{K}$-step; $\mathrm{V}_{\mathrm{j}}$ - the relative variable fluorescence at the J-step; $\mathrm{V}_{\mathrm{PSI}}-\mathrm{MR} / \mathrm{MR}_{0}$ maximal slope descending; $\mathrm{V}_{\mathrm{PSI}}+\mathrm{PSII}-\mathrm{MR} / \mathrm{MR}_{0}$ maximal slope increasing.

\begin{tabular}{lllllll}
\hline Treatment & $\mathrm{F}_{\mathrm{v}} / \mathrm{F}_{\mathrm{m}}$ & $\mathrm{V}_{\mathrm{j}}$ & $\mathrm{W}_{\mathrm{k}}$ & $\mathrm{PI}_{\mathrm{ABS}}$ & $\mathrm{V}_{\text {PSI }}$ & $\mathrm{V}_{\text {PSI }+ \text { PSII }}$ \\
\hline $\mathrm{CK}$ & $0.82 \pm 0.02^{\mathrm{ab}}$ & $0.52 \pm 0.02^{\mathrm{bc}}$ & $0.26 \pm 0.01^{\mathrm{d}}$ & $2.46 \pm 0.05^{\mathrm{c}}$ & $0.00210 \pm 0.00002^{\mathrm{c}}$ & $0.00520 \pm 0.00009^{\mathrm{a}}$ \\
$\mathrm{SA} 1$ & $0.78 \pm 0.02^{\mathrm{bc}}$ & $0.53 \pm 0.03^{\mathrm{bc}}$ & $0.31 \pm 0.02^{\mathrm{bcd}}$ & $2.09 \pm 0.19^{\mathrm{d}}$ & $0.00210 \pm 0.00003^{\mathrm{c}}$ & $0.00390 \pm 0.00005^{\mathrm{b}}$ \\
$\mathrm{SA} 2$ & $0.74 \pm 0.01^{\mathrm{cd}}$ & $0.57 \pm 0.03^{\mathrm{ab}}$ & $0.38 \pm 0.02^{\mathrm{bcd}}$ & $1.84 \pm 0.06^{\mathrm{e}}$ & $0.00250 \pm 0.00003^{\mathrm{bc}}$ & $0.00380 \pm 0.00004^{\mathrm{b}}$ \\
$\mathrm{SA3}$ & $0.70 \pm 0.02^{\mathrm{d}}$ & $0.60 \pm 0.04^{\mathrm{ab}}$ & $0.40 \pm 0.04^{\mathrm{abc}}$ & $1.51 \pm 0.09^{\mathrm{f}}$ & $0.00290 \pm 0.00004^{\mathrm{ab}}$ & $0.00210 \pm 0.00007^{\mathrm{c}}$ \\
$\mathrm{SA} 4$ & $0.68 \pm 0.01^{\mathrm{d}}$ & $0.67 \pm 0.01^{\mathrm{a}}$ & $0.52 \pm 0.01^{\mathrm{a}}$ & $1.16 \pm 0.09^{\mathrm{d}}$ & $0.00310 \pm 0.00001^{\mathrm{a}}$ & $0.00180 \pm 0.00006^{\mathrm{c}}$ \\
PA1 & $0.85 \pm 0.01^{\mathrm{ab}}$ & $0.51 \pm 0.01^{\mathrm{bc}}$ & $0.28 \pm 0.01^{\mathrm{cd}}$ & $2.69 \pm 0.08^{\mathrm{b}}$ & $0.00220 \pm 0.00001^{\mathrm{c}}$ & $0.00530 \pm 0.00002^{\mathrm{a}}$ \\
PA2 & $0.87 \pm 0.01^{\mathrm{a}}$ & $0.43 \pm 0.05^{\mathrm{c}}$ & $0.29 \pm 0.02^{\mathrm{cd}}$ & $2.97 \pm 0.23^{\mathrm{a}}$ & $0.00210 \pm 0.00005^{\mathrm{c}}$ & $0.00380 \pm 0.00012^{\mathrm{b}}$ \\
PA3 & $0.74 \pm 0.02^{\mathrm{cd}}$ & $0.58 \pm 0.02^{\mathrm{ab}}$ & $0.41 \pm 0.03^{\mathrm{abc}}$ & $2.20 \pm 0.09^{\mathrm{d}}$ & $0.0020 \pm 0.00002^{\mathrm{c}}$ & $0.00360 \pm 0.00018^{\mathrm{b}}$ \\
PA4 & $0.70 \pm 0.01^{\mathrm{d}}$ & $0.63 \pm 0.03^{\mathrm{ab}}$ & $0.44 \pm 0.02^{\mathrm{ab}}$ & $1.68 \pm 0.07^{\mathrm{ef}}$ & $0.00190 \pm 0.00003^{\mathrm{c}}$ & $0.00360 \pm 0.00009^{\mathrm{b}}$ \\
\hline
\end{tabular}

The $\mathrm{F}_{\mathrm{v}} / \mathrm{F}_{\mathrm{m}}$ values of the strawberry leaves increased by 3.3 and 5.4\% after the P1 and P2 treatments, respectively, compared with the control; however, the other phenolic acid treatments resulted in lower $\mathrm{F}_{\mathrm{v}} / \mathrm{F}_{\mathrm{m}}$ values than that of the control. The most significant decrease in the $\mathrm{F}_{\mathrm{v}} / \mathrm{F}_{\mathrm{m}}$ was observed after the S4 treatment, which only accounted for $82.9 \%$ of the control. The $\mathrm{PI}_{\mathrm{ABS}}$ reflects the overall performance of PSII in plant leaves. With the increasing concentration of exogenous $\mathrm{SA}$, the $\mathrm{PI}_{\mathrm{ABS}}$ of the strawberry leaves showed a downward trend, with 85.1, $75.1,61.3$, and $47.3 \%$ decreases in S1-S4, respectively, relative to the control values. After the treatment with the low PA concentrations, $\mathrm{PI}_{\mathrm{ABS}}$ increased by 9.3 and $20.7 \%$ in $\mathrm{P} 1-\mathrm{P} 2$, while the treatment with the high PA concentrations this parameter was markedly decreased by 10.6 and $31.7 \%$ in P3-P4 compared with the control (Table 2 ). The study showed that treatment with different phenolic acid concentrations could impair both the donor side of OEC and acceptor side $\mathrm{Q}_{\mathrm{A}}$ of PSII in the strawberry leaves, which significantly inhibited the overall function of PSII and ultimately affected the transport rate of photosynthetic electrons in the electron transport chain. The effect of exogenous SA was greater than that of PA on PSII functions in strawberry leaves, and this negative effect was more significant under higher concentrations.

PSI Chl fluorescence characteristics: $V_{\text {PSI, which is a }}$ fluorescence parameter indicating the redox capacity of PSI, exhibited an upward trend with increasing concentration of SA (Table 2). The values significantly increased by 38.1 and $47.6 \%$ for the S3 and S4 treatments, respectively, compared with the control. However, $\mathrm{V}_{\text {PSI+PSII }}$ exhibited a clear downward trend at the slow-rising phase of $\mathrm{MR} / \mathrm{MR}_{0}$. There was no significant difference in $\mathrm{V}_{\mathrm{PSI}}$ following treatment with different exogenous PA concentrations compared with the control. With the exception of the P1 treatment, the $\mathrm{V}_{\text {PSI+PSII }}$ exhibited a slight downward trend for the PA treatment concentrations. The study 
showed that exogenous phenolic acid treatments could affect the overall redox capacity of the PSI in strawberry leaves. The effect of SA treatment was more significant

\section{Discussion}

Obstacles to continuous cropping can lead to total crop destruction and have serious adverse consequences for the healthy development of the strawberry industry. One of the main obstacles to continuous cropping is the accumulation of phenolic acids.

Significant positive effects of low PA concentrations on Chl $a, \mathrm{Chl} b$, total Chl, and Car contents were observed in the present study, whereas the synthesis of photosynthetic pigments in strawberry seedlings were significantly inhibited at higher concentrations. These promoting effects at low concentrations and inhibiting effects at high concentrations are similar to those reported by $\mathrm{Hu}$ et al. (2013). However, SA treatments inhibited the synthesis of photosynthetic pigments in strawberry seedlings, and this inhibitory effect was gradually enhanced with the increasing SA concentration, similarly to the effect of phenolic acids on Chl accumulation in rice (Yang 2002).

Many studies have demonstrated that chemical substances can affect photosynthesis in plants as well as other physiological and biochemical processes (Einhelling et al. 1995). Chemical substances can affect photosynthesis directly by affecting not only stomatal factors, such as $E$, $g_{\mathrm{s}}$, and $C_{\mathrm{i}}$, but also by nonstomatal factors, such as photosynthetic pigments. According to Einhelling et al. (1979), phenolic acids, such as ferulic acid and caffeic acid, can inhibit plant growth by reducing photosynthesis, $\mathrm{Chl}$ content, and $g_{\mathrm{s}}$ in leaves. The results of the present study suggest that $g_{\mathrm{s}}, P_{\mathrm{N}}$, and $C_{\mathrm{i}}$ were enhanced at low concentrations of PA and inhibited at high concentrations. We showed that the allelochemicals permeated through the plant after treatment with high concentrations of PA, which destroyed the photosynthetic apparatus and inhibited photosynthesis and growth. By contrast, low concentrations of PA $\left(4 \mathrm{~g} \mathrm{~g}^{-1}\right)$ might enhance $E$ and supply $\mathrm{CO}_{2}$ in mesophyll cells by improving the stomatal opening in strawberry leaves, resulting in an increase in $P_{\mathrm{N}}$, and promoting accumulation of assimilation products. Various indexes generally showed an inhibitory effect of SA, including on the $P_{\mathrm{N}}$ and $E$. The decrease in $g_{\mathrm{s}}$ was significantly greater with the increasing SA concentration compared to increasing PA concentration, but there was no obvious difference in $C_{\mathrm{i}}$, which indicated that photosynthesis was limited by nonstomatal factors in strawberry. This study also showed that phenolic acid treatment had no significant effect on Chl fluorescence parameters at low concentrations $\left(4 \mu \mathrm{g} \mathrm{g}^{-1}\right)$ but significantly reduced the photochemical quenching coefficient in strawberry seedlings, resulting in decrease in $F_{v} / F_{m}$ to different degrees at high concentrations $\left(27 \mu \mathrm{g} \mathrm{g}^{-1}\right)$. Therefore, both types of phenolic acid treatments can decrease primary light energy conversion by PSII and ETR than that of PA treatment, and the effect was dependent on the treatment concentration.

at high concentrations. This decrease reduced the production of ATP and the rate of carbon assimilation, thus affecting the accumulation of strawberry assimilation products and reducing the strawberry biomass.

The $\mathrm{PI}_{\mathrm{ABS}}$, which can sensitively reflect the overall function of the photosynthetic apparatus in plants, is an important indicator for the photoinhibition of PSII under abiotic stress ( $\mathrm{Yu}$ 2006). In our experiment, both types of phenolic acids caused a decrease in the $\mathrm{F}_{\mathrm{v}} / \mathrm{F}_{\mathrm{m}}$ and $\mathrm{PI}_{\mathrm{ABS}}$ in strawberry leaves, thereby impairing the function of the entire PSII. However, the resulting excitation energy was transported from PSII to PSI through plastocyanin, which might impair the PSI functions to some extent. As the concentration of exogenous phenolic acids increased, the $\mathrm{P}_{700}$ content, which was indicative of the PSI redox reaction, showed a significant downward trend. According to the changes in $\mathrm{V}_{\mathrm{PSI}+\mathrm{PSII}}$, the ETR from PSII to $\mathrm{P}_{700}$ in an oxidation state excited by red light was significantly decreased. As shown by the changes in $V_{\text {PSI, the }}$ independent oxidation-reduction rate of $\mathrm{P}_{700}$ increased before the electrons were transported from PSII to PSI by treatments with the increasing phenolic acid concentrations. The degradation of the antenna pigment in PSI was slower than the degradation of $\mathrm{P}_{700}$ in the reaction centre, possibly because the phenolic acids affected the ratio of the antenna pigment to the PSI reaction centre pigment. The significant decrease in PSI activity could be attributable to PSI impairment. Another possible explanation is that the PSII acceptor side was seriously impaired and failed to supply electrons to PSI normally, leading to unsynchronized degradation of the antenna pigment and the PSII and PSI reaction centre pigments. Consequently, the PSI and PSII activities markedly declined and the coordination of PSI and PSII was damaged, thereby affecting the normal transport of photosynthetic electrons. The treatment with low phenolic acid concentrations did not seriously impair the photosynthetic apparatus, and the PSII and PSI functions appeared to be in a normal state. In summary, impairment of either PSI or PSII could affect the functions of the entire photosynthetic apparatus, resulting in a decrease in the photosynthetic efficiency and biomass. However, which photosystem was impaired more seriously under phenolic acid stress and the critical sites of action by phenolic acids are still unclear and are the focus of our next study.

Conclusion: Exogenous phenolic acids decreased the photosynthetic pigment contents, altered the composition of photosynthetic pigments, and affected the photosynthetic capacity of strawberry leaves. High exogenous phenolic acid concentrations impaired the donor and 
acceptor sides of PSII, thereby affecting ETR. Furthermore, this change caused a reduction in the redox capacity of PSI and therefore affected the overall function and ETR

\section{References}

Asaduzzaman M., Asao T.: Autotoxicity in beans and their allelochemicals. - Sci. Hortic.-Amsterdam 134: 26-31, 2012.

Asao T., Kitazawa H., Ban T.: Electrodegradation of root exudates to mitigate autotoxicity in hydroponically grown strawberry (Fragaria $\times$ ananassa Duch.) plants. - HortSci. 43: 2034-2038, 2008.

Blum A.: Drought resistance, water-use efficiency, and yield potential: are they compatible, dissonant, or mutually exclusive? - Aust. J. Agr. Res. 56: 1159-1168, 2005.

Cao K.Q., Wang S.T.: Autotoxicity and soil sickness of strawberry (Fragaria $\times$ ananassa Duch.). - Allelopathy J. 20: 103-113, 2007.

Einhelling F.A.: Allelopathy: Current Status and Future Goals. Pp. 1-24. Am. Chem. Soc. Press, Washington, D. C. 1995.

Einhelling F.A., Rasmussen J.A., Schon M.K.: Effects of three phenolic acids on chlorophyll content and growth of soybean and grain sorghum seedlings. - J. Chem. Ecol. 5: 815-824, 1979.

Han C.M., Pan W.N., Wu N. et al.: Allelopathic effect of ginger on seed germination and seedling growth of soybean and chive. - Sci. Hortic.-Amsterdam 116: 330-336, 2008.

Hiradate S., Morita S., Furubayashi A. et al:: Plant growth inhibition by Cis-cinnamoyl glucosides and Cis-cinnamic acid. - J. Chem. Ecol. 31: 591-601, 2005.

Hu J.W., Zhu W.X., Xu N. et al.: [Effects of exogenous phenolic acids on growth and photosynthetic characteristics of mulberry seedlings.] - Prat. Sci. 30: 1394-1400, 2013. [In Chinese]

Huang X.X., Bie Z.L., Huang Y.: Identification of autotoxins in rhizosphere soils under the continuous cropping of cowpea. Allelopathy J. 25: 383-392, 2010.

Inderjit K.M., Duke S.O.: Ecophysiological aspects of allelopathy. - Planta 217: 529-539, 2003.

Li H.S.: [Principles and Techniques of Plant Physiology and Biochemistry Experiment.] Pp. 118-119. Higher Educ. Press, Beijing 2006.[In Chinese]

Munekage Y., Hashimoto M., Miyake C. et al.: Cyclic electron flow around photosystem I is essential for photosynthesis. Nature 429: 579-582, 2004. of the photosystems, leading to a decrease in the carbon assimilation ability in the leaves. Exogenous SA treatment exhibited a stronger effect than that of PA treatment.

Schansker G., Srivastava A., Govindjee et al.: Characterization of the $820-\mathrm{nm}$ transmission signal paralleling the chlorophyll $a$ fluorescence rise (OJIP) in pea leaves. - Funct. Plant Biol. 30: 785-796, 2003

Schutter M.E., Sandeno J.M., Dick R.P.: Seasonal, soil type, and alternative management influences on microbial communities of vegetable cropping systems. - Biol. Fert. Soils. 34: 397-410, 2001.

Sun H.Z., Lin C.B., Sun W.H. et al.: [Research progress of effect of light quality on crop photosynthesis.] - J. Anhui Agri. Sci. 43: 14-16, 2015. [In Chinese]

Tan C.H., Dai H.P., Lei J.J.: [Current situation and development trend of strawberry production and trade in the world.] - World Agr. 3: 10-12, 2003.[In Chinese]

Wang Y.F., Pan F.B., Zhang X.F. et al.: [Effects of phenolic acids on growth and photosynthetic characteristics of seedlings of Malus hupehensis.] - Sci. Silvae Sin. 2: 53-59, 2015. [In Chinese]

Yang C.M., Lee C.N., Chou C.H.: Effect of three allelopathic phenolics on chlorophyll accumulation of rice (Oryza sativa) seedlings: Inhibition of supply orientation. - Bot. Bull. Acad. Sin. 43: 299-304, 2002

Yu J.H., Zhang Y., Niu C.X. et al.: [Effects of two kinds of allelochemicals on photosynthesis and chlorophyll fluorescence parameters of Solanum melongena L. seedlings.] - Chin. J. Appl. Ecol. 17: 1629-1632, 2006. [In Chinese]

Zhang K.M., Shen Y., Zhou X.Q. et al.: Photosynthetic electrontransfer reactions in the gametophyte of Pteris multifida reveal the presence of allelopathic interference from the invasive plant species Bidens pilosa. - J. Photoch. Photobio. B. 158: 81-88, 2016.

Zhang Z.S., Jia Y.J., Gao H.Y. et al.: Characterization of PSI recovery after chilling - induced photoinhibition in cucumber (Cucumis sativus L.) leaves. - Planta 234: 883-889, 2011.

Zhen W.C.: [Study on the mechanism and control measures of strawberry replant disease]. - J. Hebei Agr. Univ., Baoding, 003. [In Chinese] 